\title{
Spectrum of Changes in Gastric Mucosa with Helicobacter Pylori Infection
}

\author{
Ghimire $P G^{1}$, Ghimire $P^{2}$, Goel $R G^{3}$, Bahl DV
}

\begin{abstract}
Aim: To evaluate the spectrum of mucosal changes in endoscopy guided gastric biopsies and analyze the association of Helicobacter pylori with demographic factors. Materials and Methods: It was a cross sectional analytical study conducted in the Department of Pathology during the period from December 2011 to April 2012. A total of 52 endoscopic biopsy specimens, each fulfilling the inclusive criteria were selected and processed using standard histopathological technique and stained with Haematoxylin-Eosin stain and modified Giemsa stain for Helicobacter pylori. Histopathological, ultrasonographic and endoscopic findings were correlated. Data were analyzed using SPSS 17. Results: Out of 52 cases enrolled in our study, $29(55.8 \%)$ were males and $23(44.2 \%)$ were females with a male: female ratio of 1.2:1. H. pylori infection was present in $16(30.8 \%)$ of biopsies and was significantly greater in the younger age group between 21 to 40 years ( $p$ value $<0.024$ ). Histopathological examination showed atrophy of the gastric mucosa in $18(34.6 \%)$ cases, dysplasia in one and intestinal metaplasia in three cases. Statistically significant relation ( $p$ value $<0.006)$ was seen between $\mathrm{H}$. pylori and mucosal atrophy. No significant association was seen between gender and presence of $\mathrm{H}$. pylori in the gastric mucosa ( $p$ value $<0.16$ ). Conclusions: Histopathological study of endoscopic biopsy showed spectrum of changes in symptomatic cases. H pylori was seen significantly in younger age with atrophy of gastric mucosa as a significant finding.
\end{abstract}

Key words: Endoscopic gastric biopsy, helicobacter pylori, mucosal atrophy

\section{INTRODUCTION}

Upper gastrointestinal endoscopy (UGI) has been an indispensable tool in the evaluation of patients who present with dyspepsia. Several non-specific symptoms thought to originate from the gastrointestinal tract are collectively termed as dyspepsia. Helicobacter pylori (H.pylori), a Gram negative urease producing bacterium has been associated with many benign forms of gastritis, peptic ulcer disease and malignancies as gastric adenocarcinoma and gastric mucosa-associated lymphoid tissue (MALT) lymphoma in adults ${ }^{1}$. This study was performed to detect Helicobacter pylori and the spectrum of changes in gastric mucosa in endoscopy guided gastric biopsies.

\section{MATERIALS AND METHODS:}

It was a cross sectional analytical study conducted in the Department of Pathology at Nepalgunj Medical College Teaching Hospital, Kohalpur during the period from December

\footnotetext{
1. Dr. Pragya Gautam Ghimire

2. Dr. Prasanna Ghimire

3. Prof. R. G. Goel

4. Prof. D. V. Bahl
}

2011 to April 2012. The biopsy specimens were taken by the surgeons from various regions of the upper gastrointestinal tract which included esophagus, stomach and first two parts of duodenum in patients with dyspepsia or those having alarming features in dyspepsia. Biopsy specimens ranged from three to eight in number and were fixed overnight in $10 \%$ buffered formalin, embedded in paraffin, cut to 3-4 $\mu$ m thickness using rotary microtome, and stained with Haematoxylin-Eosin stain. Histological diagnosis of gastric mucosal inflammation, gastric glandular atrophy, intestinal metaplasia and malignancy were made accordingly. Data were entered in SPSS Version 17. The descriptive and inferential statistics was used. Majority of the patients (59.6\%) belonged to 21 to 40 years of age. Chi square test was applied to see the statistical significance.

\section{RESULTS:}

Among the 52 cases enrolled in the study, 23 (44.2\%) were females and $29(55.8 \%)$ were males with a male: female ratio of $1.2: 1$ and the mean age of the patients was $39.71 \pm 15.1$ years. Patients between $21-40$ years constituted $59.6 \%$ of total.

Ultrasonographic examination revealed normal findings in most of the cases (80.8\%). Thickened antral wall was seen in three cases (Table I).

\author{
Address for correspondence: \\ Dr. Pragya Gautam Ghimire \\ Department of Pathology \\ Nepalgunj Medical College Teaching Hospital \\ Kohalpur, Banke, Nepal \\ E-mail: drpragya@gmail.com
}


Ghimire et al.: Spectrum of Changes in Gastric Mucosa with Helicobacter Pylori Infection

\begin{tabular}{|c|c|c|}
\hline Statistical & Frequency & $\%$ \\
\hline Normal & 42 & 80.8 \\
\hline Thickened antral wall & 3 & 5.8 \\
\hline Cholelithiasis & 6 & 11.5 \\
\hline Liver metastasis & 1 & 1.9 \\
\hline Total & 52 & 100 \\
\hline
\end{tabular}

Table I: Ultrasonographic findings in patients undergoing endoscopic gastric biopsies

\begin{tabular}{|c|c|c|c|c|c|c|}
\hline \multirow[b]{2}{*}{ Endoscopic Diagnosis } & \multicolumn{4}{|c|}{ Histopathological Diagnosis } & \multirow[b]{2}{*}{ Total } & \multirow[b]{2}{*}{ p-value } \\
\hline & $\begin{array}{l}\text { Chronic } \\
\text { Gastritis }\end{array}$ & Malignancy & $\begin{array}{c}\text { Acute erosive } \\
\text { Gastritis }\end{array}$ & Normal & & \\
\hline Gastritis & 27 & 0 & 1 & 1 & 29 & \multirow{6}{*}{$<0.001$} \\
\hline Gastroduodenitis & 12 & 0 & 0 & 0 & 12 & \\
\hline Carcinoma Stomach & 2 & 6 & 0 & 0 & 8 & \\
\hline Duodenal ulcer & 1 & 0 & 0 & 0 & 1 & \\
\hline Gastric ulcer & 2 & 0 & 0 & 0 & 2 & \\
\hline Total & 44 & 6 & 1 & 1 & 52 & \\
\hline
\end{tabular}

Table II: Association between endoscopic findings and final diagnosis based on histopathology

Out of 52 patients, 29 had features of gastritis in endoscopy. There was a significant correlation between UGI endoscopy and histopathological findings with $p$ value of $<0.0001$ (Table II). Antrum was the most common site for solitary involvement noted in 24 cases (46.2\%). Histopathological findings showed atrophy of gastric mucosa in 18 (34.6\%) cases, dysplasia in one and intestinal type metaplasia in three cases with rest of the cases showing mucosal inflammation. H.pylori was positive in $16(30.8 \%)$ of the total 52 cases where 14 cases were in association with atrophic gastritis. Statistically significant ( $p$ value $<0.006$ ) relation was observed between H.pylori and atrophy of the gastric mucosa (Table III).

\begin{tabular}{|l|c|c|c|c|}
\hline \multirow{2}{*}{ H. pylori } & \multicolumn{2}{|c|}{ Atrophy } & \multirow{2}{*}{ Total } & \multirow{2}{*}{ p-value } \\
\cline { 2 - 3 } & Present & Absent & & \\
\hline Absent & 9 & 29 & 38 & \multirow{2}{*}{$<0.0006$} \\
\hline Present & 9 & 5 & 14 & \\
\hline Total & 18 & 34 & 52 & \\
\hline
\end{tabular}

Table III: Correlation between H. Pylori and atrophy of gastric mucosa

No significant association was seen between the sex and presence of $\mathrm{H}$. pylori in the gastric mucosa, $\mathrm{p}$ value $<0.16$. $\mathrm{H}$. pylori was seen significantly in the young age group between 21 to 40 years of age with the $p$ value of $<0.024$.

Based on the histopathological examination 44(84.6\%) cases were diagnosed as chronic gastritis (Table IV).

\begin{tabular}{|l|c|c|}
\hline & Frequency & $\%$ \\
\hline Chronic gastritis & 44 & 84.6 \\
\hline Acute erosive gastritis & 1 & 1.9 \\
\hline Malignancies & \multicolumn{2}{|l|}{} \\
\hline Adenosquamous Carcinoma & 1 & 1.9 \\
\hline Adenocarcinoma & 4 & 7.7 \\
\hline Squamous cell carcinoma & 1 & 1.9 \\
\hline Normal & 1 & 1.9 \\
\hline Total & 52 & 100 \\
\hline
\end{tabular}

Table IV: Histopathological diagnosis in endoscopic biopsy specimens

Out of 52 cases, six were malignant with adenocarcinoma being the most common type accounting for four cases.

\section{DISCUSSION}

Upper $\mathrm{Gl}$ endoscopy has major implication in the diagnosis and management in upper $\mathrm{Gl}$ pathologies. The different expression of gastritis in antrum and body is attributed to the increased reactivity of the antral mucosa to infection, due to a possible enhanced immunologic response to $\mathrm{H}$. pylori ${ }^{1}$. Antrum has been seen as the predilection site for involvement in gastritis in Nepalese population ${ }^{2}$. H. pylori were seen significantly in the younger age group between 21 to 40 years of age. Similar results were obtained by Chong $\mathrm{VH}^{3}$. The exact reasons for these observed differences are not completely known. There 
was no gender association with $\mathrm{H}$. pylori, this is in accordance with Replogle ML et al and Malaty HM et al. ${ }^{4,5}$. Chong VH et al showed the male group had significantly higher prevalence, particularly in the 20-29, 40-49, 50-59 and $\geq 70$ years age groups. Factors such as improved standard of living and hygienic practices may account for the lower prevalence ${ }^{6}$.

Ultrasonographically, increased gastric wall thickness is evident in different gastric pathologies,. Although measurement of individual layer of stomach wall was not performed in our case; the wall thickness was within normal limits (3-6 mm) in most of the cases of gastritis. Gastric malignancies are associated with wall thickness measuring greater than $7 \mathrm{~mm}^{9}$. All our cases of gastric malignancies involving the antrum showed thickened antral wall. Genta reported that $\mathrm{H}$ pylori and inflammation was distributed evenly throughout the stomach ${ }^{10}$.

In our study antrum was the most common site. Glandular atrophy and intestinal metaplasia were significantly associated with $\mathrm{H}$ pylori. Occasionally, $\mathrm{H}$ pylori is negative in glandular atrophy and intestinal metaplasias while in the tissues without glandular atrophy or intestinal metaplasia it might be found $\mathrm{H}$ pylori positive. This result is in accordance with the epidemiologic and pathologic studies of Correa, which revealed the temporal association of chronic superficial gastritis, atrophic gastritis, intestinal metaplasia, epithelial dysplasia, and finally gastric cancer evolution ${ }^{11}$. These findings suggest that most patients with intestinal metaplasia and glandular atrophy have been infected with $\mathrm{H}$ pylori at some stage. $\mathrm{H}$ pylori infection may provide the proper environment for atrophic gastritis and intestinal metaplasia to occur. At the final stage of the disease, gastric atrophy with intestinal metaplasia is not a hospitable environment for $\mathrm{H}$ pylori and is associated with a dramatic reduction or even disappearance of the organism $^{12-16}$.

However; this will require further studies to assess if there is an association. There are several limitations with our study. Firstly, our study was done on a small sample size and secondly association with other factors like socioeconomic status and education were not done.

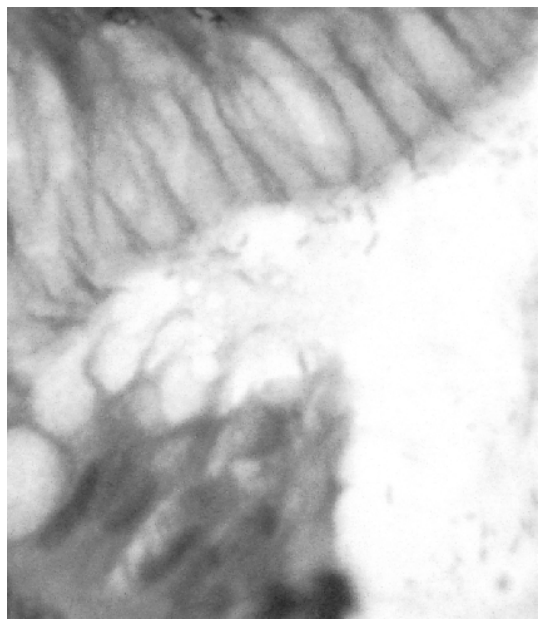

Figure 1: H.pylori organisms seen lying over the surface mucous cells of gastric mucosa (H \& E × 100)
In conclusion, our study showed spectrum of changes in endoscopy guided gastric biopsy in symptomatic cases. H pylori was seen significantly in younger age with atrophy of gastric mucosa as a significant finding.

\section{REFERENCES}

1. Bayerdorffer E, Lehn N, Hatz R, Mannes GA, Oertel H, Sauerbruch $\mathrm{T}$, et al. Difference in expression of Helicobacter pylori gastritis in antrum and body. Gastroenterology. 1992;102(5):1575-82.

2. Matsuhisa T, Miki M, Yamada N, Sharma SK, Shrestha BM. Helicobacter pylori infection, glandular atrophy, intestinal metaplasia and topography of chronic active gastritis in the Nepalese and Japanese population: the age, gender and endoscopic diagnosis matched study. Kathmandu Univ Med J (KUMJ). 2007;5(3):295-301.

3. Chong VH, Lim KC, Rajendran N. Prevalence of active Helicobacter pylori infection among patients referred for endoscopy in Brunei Darussalam. Singapore Med J. 2008;49(1):42-6.

4. Malaty HM, El-Kasabany A, Graham DY, Miller CC, Reddy SG, Srinivasan SR, et al. Age at acquisition of Helicobacter pylori infection: a follow-up study from infancy to adulthood. Lancet. 2002;359(9310):931-5.

5. Replogle ML, Glaser SL, Hiatt RA, Parsonnet J. Biologic sex as a risk factor for Helicobacter pylori infection in healthy young adults. Am J Epidemiol. 1995;142(8):856-63.

6. Everhart JE, Kruszon-Moran D, Perez-Perez GI, Tralka TS, McQuillan G. Seroprevalence and ethnic differences in Helicobacter pylori infection among adults in the United States. J Infect Dis. 2000;181(4):1359-63.

7. Bolondi L, Casanova P, Santi V, Caletti G, Barbara L, Labo G. The sonographic appearance of the normal gastric wall: an in vitro study. Ultrasound Med Biol. 1986;12(12):991-8.

8. Mazaher H, Farahmand F, Khanali F, Bozorg S, Esfe A, Mahjoub F, et al. Ultrasonographic evaluation of gastroduodenal wall thickness for prediction of gastritis and Helicobacter pylori infection in children. Iranian Journal of Radiology. 2010;7(1):316.

9. Suk KT, Lim DW, Kim MY, Park DH, Kim KH, Kim JM, et al. Thickening of the gastric wall on transabdominal sonography: a sign of gastric cancer. J Clin Ultrasound. 2008;36(8):462-6.

10. De Idiaquez D, Bussalleu A, Rodrigo I, Cabello J, Caviedes G, Cok J, et al. [Helicobacter Pylori Infection Erradication in Dispeptic Patients with and without Peptic Ulcer]. Rev Gastroenterol Peru. 1999;19(3):179-94.

11. Kato I, Vivas J, Plummer M, Lopez G, Peraza S, Castro D, et al. Environmental factors in Helicobacter pylori-related gastric precancerous lesions in Venezuela. Cancer Epidemiol Biomarkers Prev. 2004;13(3):468-76.

12. Abraham SC, Montgomery EA, Singh VK, Yardley JH, Wu TT. Gastric adenomas: intestinal-type and gastric-type adenomas differ in the risk of adenocarcinoma and presence of background mucosal pathology. Am J Surg Pathol. 2002;26(10):1276-85.

13. Boussioutas A, Li H, Liu J, Waring P, Lade S, Holloway AJ, et al. Distinctive patterns of gene expression in premalignant gastric mucosa and gastric cancer. Cancer Res. 2003;63(10):2569-77.

14. Crabtree JE, Farmery SM. Helicobacter pylori and gastric mucosal cytokines: evidence that CagA-positive strains are more virulent. Lab Invest. 1995;73(6):742-5.

15. Kapadia CR. Gastric atrophy, metaplasia, and dysplasia: a clinical perspective. J Clin Gastroenterol. 2003;36(5 Suppl):S29-36; discussion S61-2.

16. Rugge M, Correa P, Dixon MF, Fiocca R, Hattori T, Lechago J, et al. Gastric mucosal atrophy: interobserver consistency using new criteria for classification and grading. Aliment Pharmacol Ther. 2002;16(7):1249-59. 